\title{
CEVA'S TRIANGLE INEQUALITIES
}

\section{ÁRPÁD BÉNYI AND BRANKO ĆURGUS}

Abstract. We characterize triples of cevians which form a triangle independent of the triangle where they are constructed. This problem is equivalent to solving a three-parameter family of inequalities which we call Ceva's triangle inequalities. Our main result provides the parametrization of the solution set.

Mathematics subject classification (2010): Primary 26D07, 51M04; secondary 51M15, $15 \mathrm{~B} 48$.

Keywords and phrases: Triangle inequality, triangle inequality for cevians, cone preserving matrices, common invariant cone.

\section{REFERENCES}

[1] O. Bottema, R. Ž. Djordjević, R. R. Janić, D. S. Mitrinović, P. M. Vasić, Geometric inequalities, Wolters-Noordhoff Publishing, Groningen, 1969.

[2] J. L. Brown JR., Solution to E 1366, Amer. Math. Monthly 67 (1960), 82-83.

[3] M. HAJJA, On nested sequences of triangles, Results in Mathematics 54 (2009), 289-299.

[4] M. HAJJA, The sequence of generalized median triangles and a new shape function, Journal of Geometry 96 (2009), 71-79.

[5] M. S. KLamkin, Second solution to 'Aufgabe 677', Elem. Math. 28 (1973), 129-130.

[6] D. W. MitcheLl, A Heron-type formula for the reciprocal area of a triangle, Mathematical Gazette 89 (November 2005), 494.

[7] D. S. Mitrinović, J. E. PeČArić, V. Volenec, Recent advances in geometric inequalities, Mathematics and its Applications (East European Series), 28. Kluwer Academic Publishers Group, Dordrecht, 1989.

[8] V. PRotasov, When do several linear operators share an invariant cone?, Linear Algebra Appl. 433 (2010), 781-789.

[9] L. Rodman, H. Seyalioglu, I. Spitkovs Ky, On common invariant cones for families of matrices, Linear Algebra Appl. 432 (2010), 911-926. 